\title{
The Institutional Challenges of Payment for Ecosystem Service Program in China: A Review of the Effectiveness and Implementation of Sloping Land Conversion Program
}

\section{Cheng Chen ${ }^{1,2, *}$, Hannes J. König ${ }^{1}$, Bettina Matzdorf ${ }^{1}$ and Lin Zhen ${ }^{3}$}

1 Leibniz-Centre for Agricultural Landscape Research, Eberswalder Str. 84, 15374 Müncheberg, Germany; E-Mails: hkoenig@zalf.de (H.J.K.); matzdorf@zalf.de (B.M.)

2 Department of Agricultural Economics, Humboldt-University of Berlin, Invalidentr.42, 10115 Berlin, Germany

3 Institute of Geographic Sciences and Natural Resources Research, Chinese Academy of Sciences, 11A Datun Road, Chaoyang District, 100101 Beijing, China; E-Mail: zhenl@igsnrr.ac.cn

* Author to whom correspondence should be addressed; E-Mail: cheng.chen@zalf.de; Tel.: +49-3343282-404; Fax: +49-3343282-308.

Academic Editor: Yu-Pin Lin

Received: 25 December 2014 / Accepted: 30 April 2015 / Published: 7 May 2015

\begin{abstract}
This study is an overview of the effectiveness and institutional challenges of China's Sloping Land Conversion Program (SLCP). The SLCP is the Chinese government's largest Payment for Ecosystem Services (PES) program and one of the largest PES programs in the world. From an institutional perspective, the SLCP is particularly interesting because it represents a hybrid governance type that includes both voluntary and hierarchical (top-down) elements rather than traditional command-and-control approach. Our analysis is based on a literature review that encompasses 164 international scientific articles. To identify institutional challenges, we linked the results regarding the effectiveness of the program to its institutional aspects. Our SLCP case study highlights the dependence of the effectiveness of a governmental PES program on the specific regulatory institutional setting and the particular actors involved. Our results show that some institutional challenges undermine the anticipated advantages of PES (local participation) and eventually reshape the program outcomes through implementation process, particularly in cases of hybrid governance structures in which institutional requirements are as important as the design of the specific financial incentives. The collaboration between relevant government actors at different hierarchical levels, and specifically the motivations and interests of the government actors
\end{abstract}


responsible for the implementation on the ground, play crucial roles. The SLCP can be an important milestone in environmental policy in China and the world, if more innovative elements of a theoretically ideal PES - such as local flexibility and self-interest (or at least the acceptance of the service providers supplying the relevant ecosystem services) can be strengthened. The environmental goals can be achieved in combination with greater self-interest of the applicable government actors on all hierarchical levels.

Keywords: grain for green program; land set-aside program; effectiveness of implementation; hybrid governance; PES; sustainability

\section{Introduction}

Payments for Ecosystem Services (PES) are an increasingly popular way to manage ecosystems [1]. In addition to using market forces for the efficient allocation of user rights to natural resources, the “...PES philosophy argues for the internalization of environmental externalities through the creation of markets and quasi-markets" [2]. This notion is linked to the Coase Theorem [3], which holds that the problem of external effects can be overcome under certain conditions through private negotiations between affected parties. However, Coase negotiations do not represent the ideal market situation for the environment [4]. In accordance with this understanding, within PES schemes, people do not buy and sell ecosystem services (ES), as some authors argue [5], but instead buy and sell bundles of use rights over ES [6].

In both practice and research [7], the concept of PES has been broadened to include government payments, which function as a PES-like mechanism [8]. This broad concept of PES is consistent with the Pigouvian approach [7], through which government either pays itself or makes others pay on behalf of beneficiaries [6,9]. The term PES is used as a broad umbrella [10] term for any type of conservation instruments that employ positive financial incentives. The governance model beyond the pure market-based PES system is often a hybrid type in the sense of Vatn [11]. The state represents an important actor not only as a financier but also as a legal driver [9]. Consequently, the effectiveness and efficiency of PES schemes depend on the interplay of all the institutions and actors involved. The actors are frequently connected by more than purely economic relationships [11].

The advantage of PES schemes over conventional command-and-control measures is based on the argument that social negotiations and voluntary approaches perform better in terms of cost-efficiency and local acceptance, in particular. This fact must be considered when PES systems are discussed as an innovative conservation approach that supports proactive action, replication, and stakeholder participation, that spurs competition, and that produces new sources of funding and positive side-effects [12]. Thus, on the one hand, if command-and-control institutions dominate all of PES governance, these advantages can be limited. On the other hand, there are good arguments that hybrid institutions, including command-and-control approaches, are frequently the most appropriate to consider in complex social-ecological systems [13].

The analysis of this type of hybrid governance PES approach seems most useful in learning about the interaction of different institutions and actors and how the institutional setting is correlated with the 
effectiveness of a PES scheme. China has one of the world's largest hybrid governmental PES programs. With its rapid economic growth over the past three decades, China's environmental degradation has also accelerated [14]. These problems have included land degradation, soil erosion, desertification, biodiversity loss, water pollution and water shortages [15]. In response to these enormous environmental challenges, China's central government launched a series of programs aimed at ecological restoration and ecosystem conservation with payment from the government in the late 1990s, and these programs are most commonly categorized under the domestic term eco-compensation [16]. This institutional arrangement was perceived as protecting and sustainably using ecosystem services to adjust the distribution of costs and benefits between different actors and stakeholders, primarily through economic measures [17]. Although the terms "eco-compensation" and "PES" are often used interchangeably [18], eco-compensation is a broader term that encompasses PES-like policies that involve direct payment by the government to individuals and community-level suppliers under market mechanisms [19], in addition to a range of other policy and program types. According to this classification, there are 24 major PES-like programs in China (see Supplementary Material 1). The targets of them range from watershed protection and soil erosion control to carbon emissions control and eco-agriculture [18]. As a typical government-financed ecological restoration program, the "Sloping Land Conversion Program" (SLCP) - also known as the "Conversion of Cropland to Forests Program" or "Grain-for-Green"-is considered one of the largest PES programs in the world [20], and its broad geographic cover [21], wide participation [22], tremendous investment [23] and institutional innovation [24] have drawn significant attention from the scientific community. This program was launched in 1999 with the goal of increasing forest cover and preventing soil erosion by converting sloping farmland into forests or grassland [25]. Consistent with PES's stated principals of volunteerism and local participation [26], the SLCP uses a public payment scheme that directly engages millions of rural households as core agents of project implementation [26]. Although there are different classifications, the SLCP is considered a PES program by a number of researchers [19,24,27].

One of the main challenges linked to PES development is the appropriate consideration of a variety of social-ecological systems, and its applicability often depends on complex institutional settings [11]. A number of studies individually assess the SLCP from mainly environmental [28], socioeconomic [29] and institutional perspectives [30], and utilize many different elements and indicators. Few studies have investigated the various situations and multiple dimensions of the SLCP, with the exception of a series of papers published by Yin et al. [31-35]. By reviewing the program in terms of its implementation efficacy, socioeconomic effects and environmental impact, Yin et al. [31] developed an integrated assessment and called for more attention to program execution and interdisciplinary research. In another article, Yin et al. [34] assessed the program's outcomes by exploring the governance of the SLCP, claiming that certain contexts under the label of "implementation" appear to be challenges to the program. Asking further questions about how to design an effective PES program, Yin et al. [35] examined the SLCP under the diagnostic framework of a social-ecological system with analyses from ecological, socioeconomic and institutional perspectives. However, Yin et al. [33] considered the SLCP one of the ecological restoration programs (ERP) in China and always took ERP, rather than the SLCP, as the research target. Particularly, whether the SLCP has been implemented effectively; how governance and policy implementation affect program outcomes; and how its performance can be improved are still not clear [30]. As suggested by He et al. [36], to understand the driving forces of the 
effect of the SLCP, efforts to contextualize the social-ecological interaction in the broader system of institutional economy are needed.

In this review, we focus on how the effectiveness of the SLCP is influenced by many design and execution contexts that fall primarily under the institutional umbrella. The primary goal of this article is to provide a literature survey on the SLCP with multiple dimensions and, in the end, to link the deviation between effectiveness criteria and program outcomes with their institutional contexts. To do so, we first gather the literature with a keyword-based web search and follow the classification from Yin et al. [32]. We sort the literature according to different indicators from environmental, socioeconomic and institutional perspectives. After an overview of research topics covered in the previous SLCP literature, our next step is to build criteria from the literature for program effectiveness. The actual "effectiveness" of an environmentally targeted conservation policy is complex and difficult to assess. There are different frameworks to measure effectiveness, such as the capital asset framework (CAF) [37] or the social-ecological system [38], and they are frequently built on a longer-term basis [34]. Here, we adapt the method from Yin et al. [39] and analyze the effectiveness from two determining positions: effective implementation and program impacts. Elements relating to implementation, such as converted areas, the survival rate and restored vegetation, can be categorized as effective implementation. Accordingly, the socioeconomic impact (e.g., change in income, labor transfer) and environmental impact (e.g., erosion control, water conservation) can be categorized as program impact. In our article, effectiveness is ultimately gauged based on effective implementation, socioeconomic impact and environmental impact. Nevertheless, the effectiveness criteria cannot always match program outcomes. Therefore, our third step is to summarize the previous findings on the deviation between effectiveness criteria and program outcomes. Fourth, we identify institutional challenges. Finally, to answer the question of how to improve the performance of the SLCP from an institutional perspective, we discuss the dependence of the identified deviation on these institutional challenges. The results of this study can help support the development and improvement of government-financed PES in China and throughout the world. Our analytical structure is shown in Figure 1.

The remainder of this paper is organized as follows. Section 2 describes the SLCP and how it is implemented. Section 3 presents an overview of the SLCP literature, focusing on current research priorities. Section 4 identifies the effectiveness criteria used in the literature, analyzes the deviation between the criteria and outcomes and summarizes the relevant institutional challenges. Section 5 discusses the dependence of the program's effectiveness criteria in an institutional setting under a hybrid governance regime. Section 6 concludes the paper. 


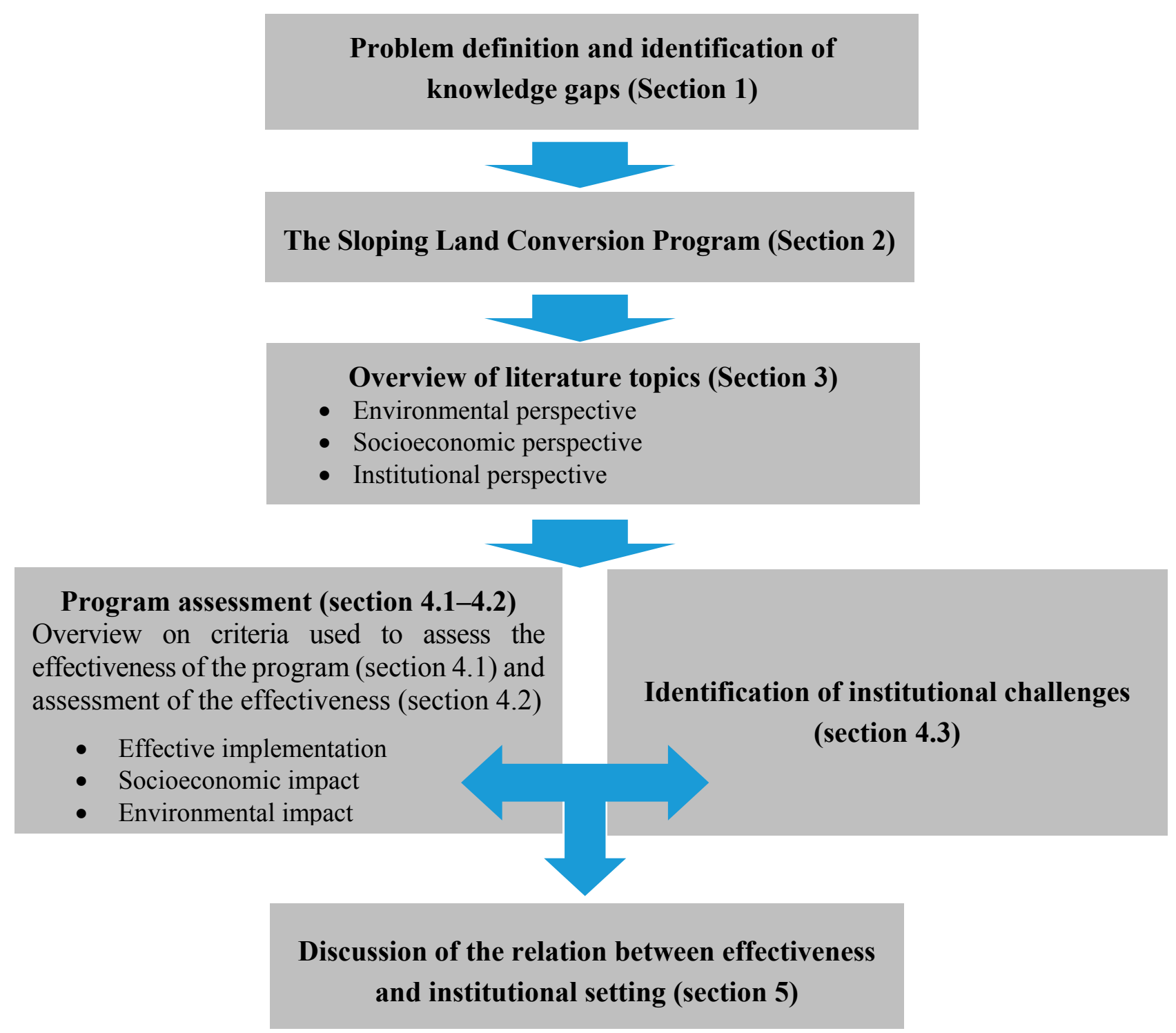

Figure 1. Analytical framework.

\section{The SLCP}

The severe drought of the Yellow River region in 1997 and the widespread flood of the Yangtze River in 1998 spurred the Chinese government to take action in response to the growing degradation of the country's forest ecosystem [24,40]. Under these circumstances, the SLCP aims to increase the country's forest and grassland cover and to reduce soil erosion, flooding, desertification and other ecological disasters [23] by retiring steeply sloping land (greater than 25 degrees) from agricultural use and returning it to forest and grassland [41]. After a pilot phase from 1999 to 2001 in three provinces, the SLCP was extended to 25 provinces. The program involved over 32 million rural households, and 257.22 billion RMB had been spent by 2010 [42]. The official goal of the SLCP was to convert approximately 14.67 million hectares of cropland to forest (4.4 million of which is on land with a slope greater than $25^{\circ}$ ), afforest 17.33 million hectares of wasteland and increase the forest cover in the enrolled area by $4.5 \%$ by 2010 [43]. Upon full implementation in 2002, the converted land jumped from 0.39 million hectares to 2.04 million, more than a fivefold increase [42]. As shown in Figure 2, after reaching its peak in 2003, new program enrollments began to decrease rapidly and almost completely 
stopped in 2007 because the central government stopped assigning liability to lower-level government in 2006. The tasks of the program thus became to consolidate the achievement on former cropland and to continue afforestation on wasteland and barren mountains [43]. By 2012, 8.0 million hectares of cropland had been retired and converted under the SLCP, which was less than $60 \%$ of its original target; the program had also established forests elsewhere on another 16.29 million hectares. Obviously, the original target for cropland retirement has not been achieved.

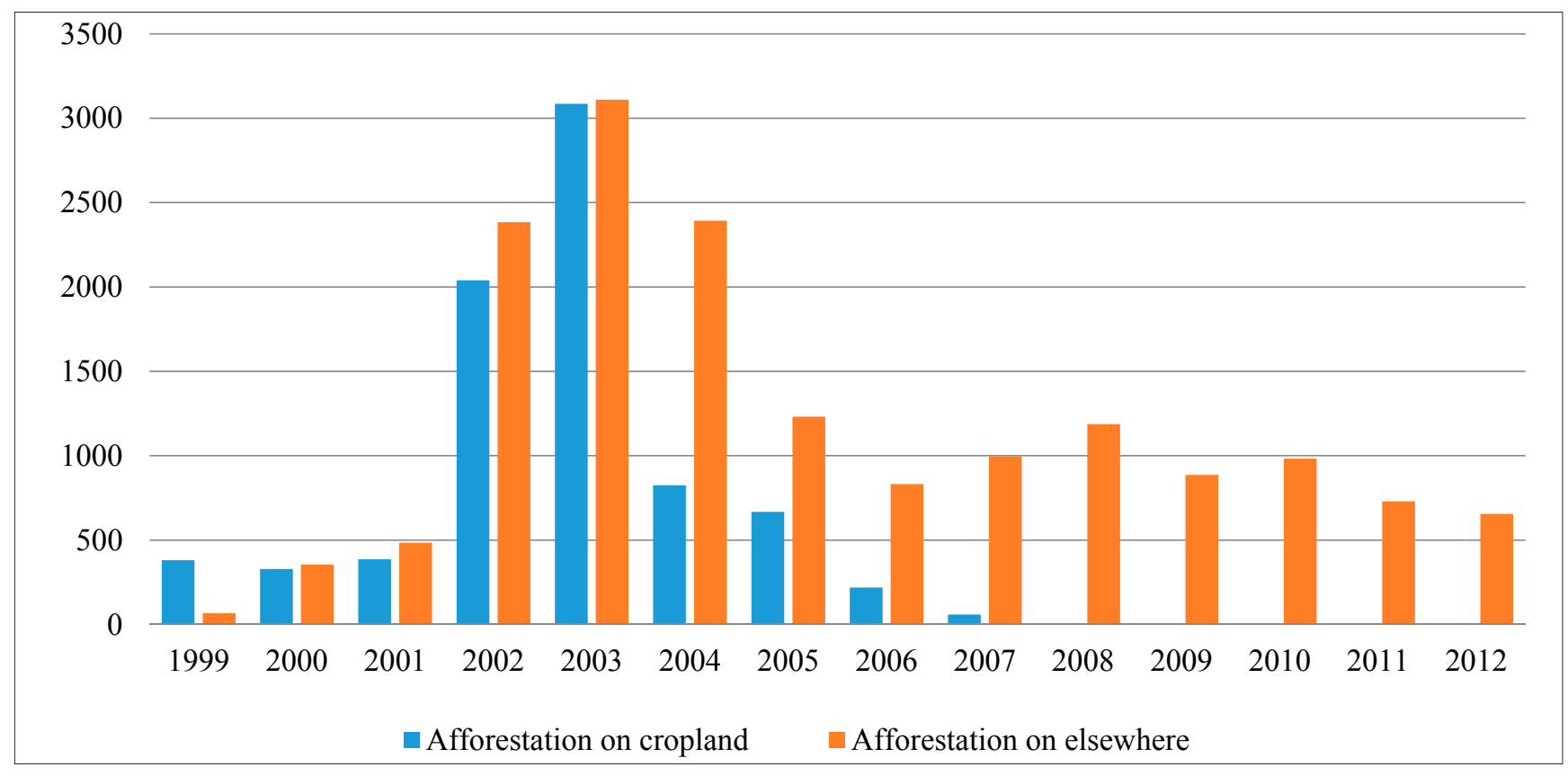

Figure 2. The Sloping Land Conversion Program implementation (unit: 1000 hectares). Source: China Forestry Statistic Yearbook 2012 [42].

The two objectives of the SLCP are to restore the nation's forests and grasslands to prevent soil erosion and to alleviate poverty in some of China's poorest regions [41]. The main instrument of the SLCP is direct compensation of households in cash, grain, or seedlings for trees by the central government. Compensation varies based on two geographical differences. Compensation in the Yangtze River Basin is higher than in the Yellow River Basin, which is in accordance with the opportunity costs of local cropland plots [31]. The period of compensation differs based on the type of conversion taking place. Households can choose either an "economic forest" (i.e., forests that produce timber, fruits, nuts, medical goods, and other commodities), an "ecological forest" (i.e., forests that provide primarily ecological functions and services) or grasslands, for periods of five years, eight years or two years, respectively [31]. However, in reality, most of the retired cropland has been planted with trees of mixed species and enrolled for eight years [23]. In 2004, the State Council issued standards for converting grain to cash at the rate of $1.4 \mathrm{RMB} / \mathrm{kg}$ because of dwindling public grain reserves [34]. In 2007, most contracts were supposed to end. To sustain the livelihood of participants, the State Council decided to extend the program for another round (2-8 years); however, the subsidy has been halved [44].

In the official annual reports, the most common indicators used to evaluate the outcomes are the enrolled area, the tree survival rate and the program acceptance rate after inspection [43]. The program is conditional in terms of land retirement but less so in terms of management of trees and grass 
established on the enrolled land, let alone the ultimate services that the restored ecosystems provide, such as erosion control and runoff regulation [33]. It is a typical "input-based PES program" in that payments are frequently made on a per-hectare basis. The SLCP's conditionality is high for retired areas and lower for successful forest plantations, which departs from the classic pattern [27].

The original institutional framework was simple: The central government provides compensation to voluntary participants for land conversion, which is presumed to improve the provision of ecosystem services in the future. This innovative feature is why the SLCP differs from most other nature conservation programs in China. It first combines a large-scale government program with direct engagement by voluntary households and village communities using financial incentives [24]. Thus, on the one hand, the government sets the rules for participation and other types of institutions, including the amount of the payment. On the other hand, implementation theoretically depends on household and village community willingness to accept the terms. This key rationale reflects the defining principle of PES, i.e., a voluntary transaction in which a land use that is likely to secure the ecosystem service is "bought" by at least one service buyer that engages with many providers [8]. By contrast, many studies have observed that because the government is the only service buyer, this type of hybrid program is typically less voluntary for the provider compared with purely market-based programs [27].

The program's design is innovative, but because implementation relies on government agencies, the SLCP remains hierarchically (top-down) structured. This type of PES can thus be characterized as hybrid governance [6]. In the implementation process, as the department in charge of the SLCP in the central government, the State Forest Administration (SFA) created the overall tasks for the entire country and assigned reforestation tasks to provincial governments by signing liability agreements [41]. The targeting of areas to retire has generally been performed via a top-down approach, beginning with retirement quotas that are distributed by the central government to the provinces and continuing on to counties, townships and, finally, participating households [45]. The onus of actual implementation has thus fallen on townships and village governments [33]. The local agencies allocate quotas, target the enrolled areas, determine the participants, distribute payments, provide technical support and monitor the program's achievements [41]. The plan for the following year evolved in the opposite fashion, from bottom to top, through an application system. Village and township governments submitted their proposed afforestation plans to each higher layer of government. In the end, the central government reviewed their plans and their achievements from the previous year and then partially or completely approved their plans [41]. Ultimately, quotas were again allocated top-down through the administrative ladder.

\section{Overall Literature Analyses}

\subsection{Dataset Establishment}

The literature search for this study was conducted in July 2014 and updated until December 2014. All names of the program ("Sloping Land Conversion Program", "Grain for Green Program China", "Conversion Cropland to Forest and Grassland Program" and "Payment for ecosystem service China") were used as keywords to search the Web of Science and the Scopus database (1999-present). No other search terms were considered because the dataset was designed to present the overall picture of the SLCP study. After careful selection, two-thirds of the reference materials unrelated to the topic of this study were excluded. Additionally, for discussion purposes, we included highly relevant literature that could 
not be found with the above strategy by pursuing the references in the literature that we had found. Ultimately, we obtained 164 journal papers covering all the study subjects (see Supplementary Material 2). The following analysis and results are based on this dataset. We acknowledge that many more studies have been published in domestic Chinese journals. However, because these studies were not written in English and most are not peer-reviewed [31], we did not include them in our dataset. It is notable that our literature search was based on defined keywords and therefore some relevant articles might have been overlooked. However, to minimize this possible bias, we carefully searched for relevant references in the available literature.

\subsection{Literature Sorting}

First, the 164 articles were sorted according to their main research topics. It should be noted that many papers address more than one topic; thus, each paper can have a maximum of three topics, although only the most important topic is considered the representative topic. Therefore, we defined the representative topic as the single topic criterion and other less important topics as multiple topic criteria. The papers were then classified into different subject categories according to their single and multiple topics. As an environmental policy, the goal of the SLCP covers many aspects, and the single and multiple criteria can be used as the indicator for comprehensive evaluation. By making this comparison, we can better understand the interdisciplinary research of the SLCP and identify the relationships among the different subjects.

After carefully reading, we selected 26 topics (detail in Figure 3) with environmental, economic, social and institutional aspects to classify our dataset. There are 13 topics related to the environment aspect, five topics related to economics aspects, five topics related to social aspects and three topics related to institutional aspects. Integrated studies and comparison studies are hard to classify, so we list them as other. Again, we acknowledge that there may be potential bias or overlapping of this classification, although we carefully select them to represent the available literature. 


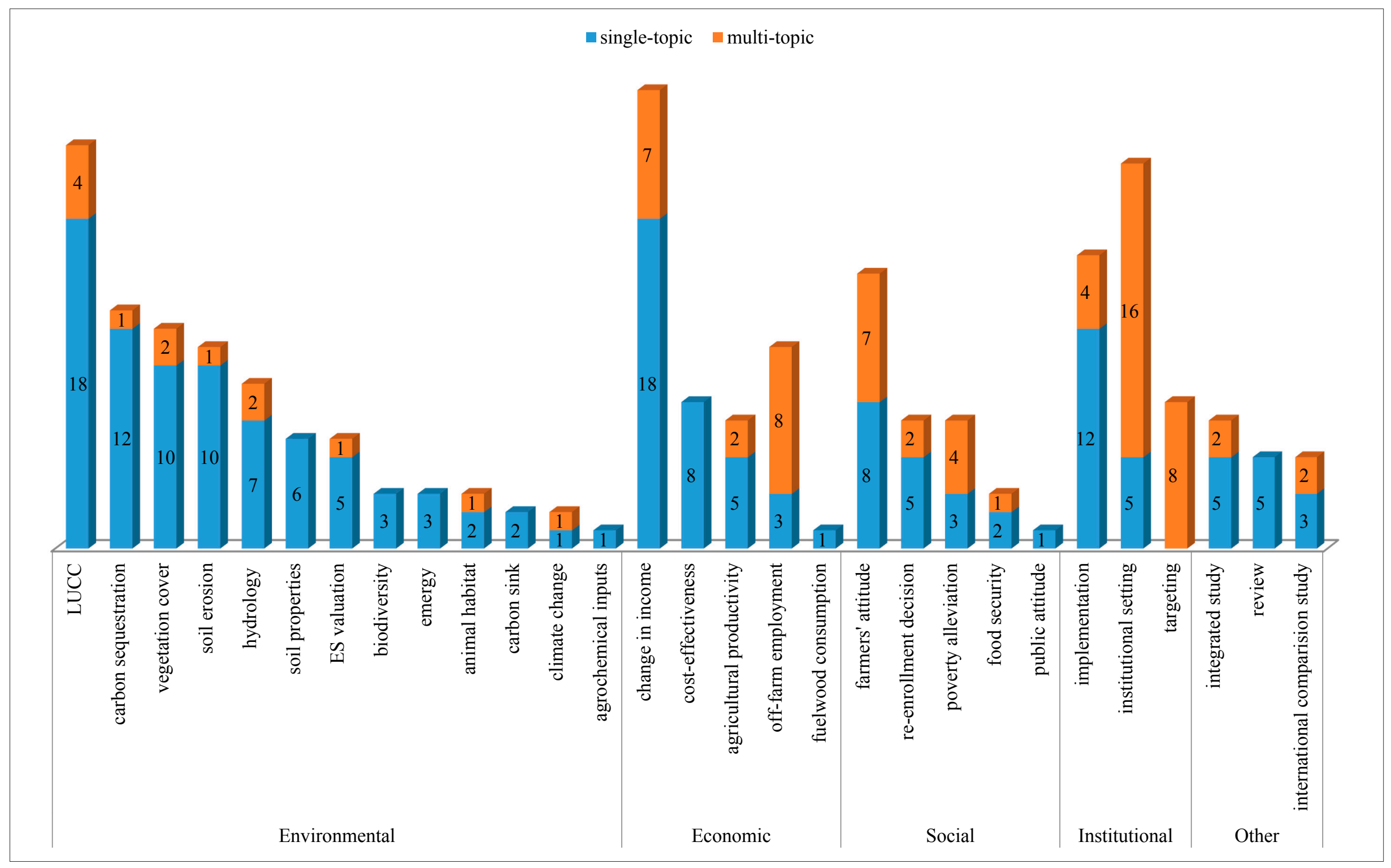

Figure 3. A classification of the literature according to research topics. 


\subsection{Research Area}

To understand the literature on the SLCP, we established environmental, social, economic, and institutional subject areas based on their single main topics. As a consequence, we obtained a result such as that shown in Figure 4.

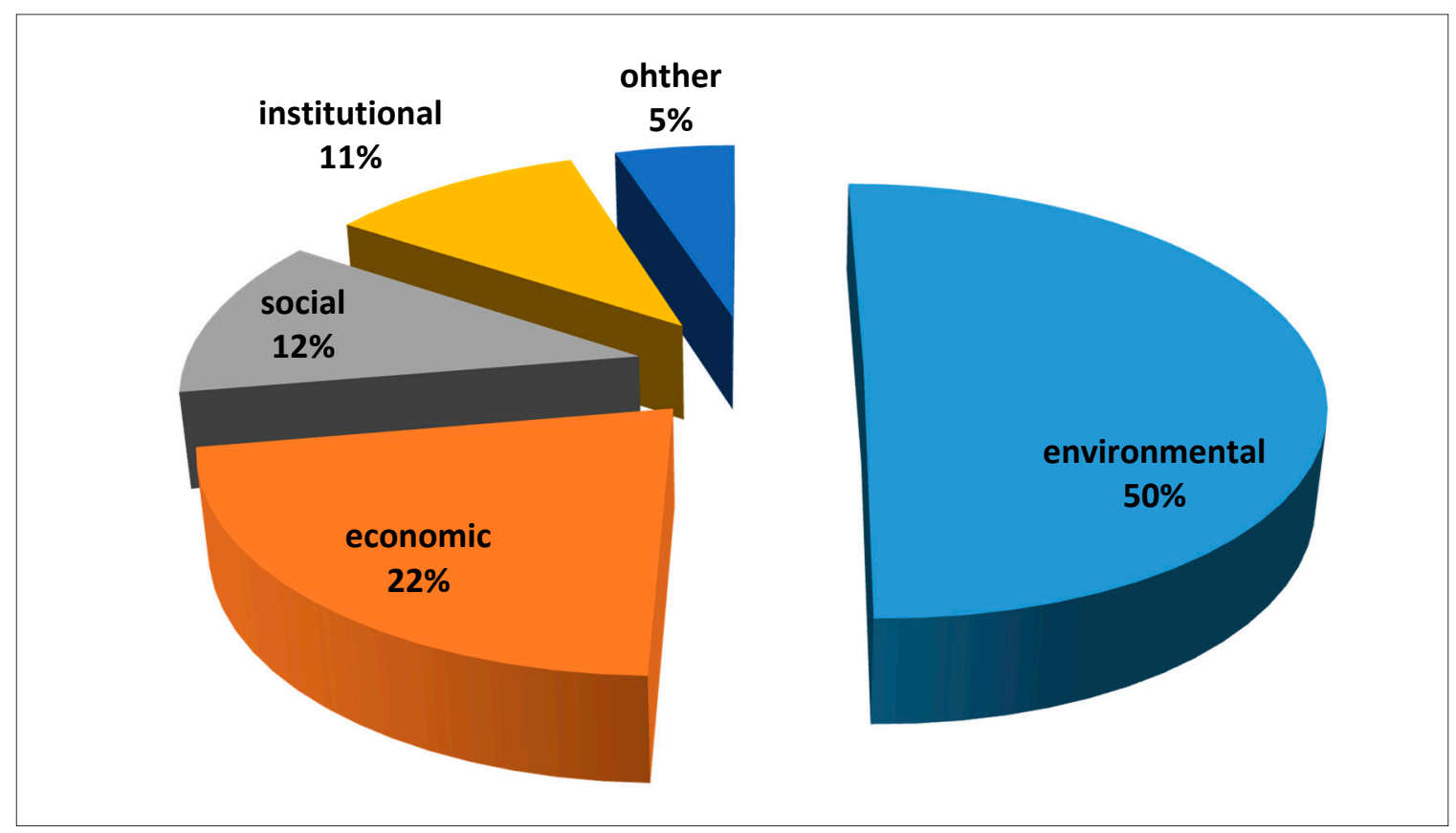

Figure 4. The subject areas of selected studies $(n=164)$.

Remarkably, half of all the published articles in international journals regarding the SLCP refer to environmental aspects. Economic aspects, social aspects, and institutional aspects are the focuses of $22 \%, 12 \%$ and $11 \%$ of the articles, respectively. Thus, the institutional aspect has drawn the least concern from the scientific community. When we examine the details, 17 articles refer to institutional studies, including 12 articles about implementation and five about institutional settings. Among these, five were contributed by a team [46] that included Michael Bennett, Zhigang Xu and Jintao Xu (as colleagues and co-authors), and their main interests were policy formulation and top-down approach implementation. Another team at Michigan State University led by Runsheng Yin [23] published four articles concerning implementation strategy, whereas other articles explored the governance of policy implementation [30], notions of justice [47], trust and property security [48], and local variations in implementation [49].

\subsection{Single and Multiple Topics}

In this section, we seek to compare the results of different paper classification methods to identify how the different aspects relate to one another (Figure 3). In the single topic criteria, changes in income (18 articles) and implementation (12 articles) drew considerable attention. Although environmental studies constituted $50 \%$ of all the research, those articles' topics are broad and scattered. There are 14 topics related to environmental aspects, but only five related to economic aspects, five related to social aspects, and two related to institutional aspects. It is clear that most papers on environmental studies 
focus on only one environmental topic, such as Land Use and Land Cover Change (LUCC), soil science, carbon sequestration or hydrology.

Including multiple topics as the criteria, the number of papers on the institutional setting increased rapidly from five to 21 and became the second most popular topic. Targeting and implementation also increased to eight and four papers, respectively. This growth made the institutional category grow from 17 papers to 45 papers. The growth came primarily from the contributions of the other three aspects. In the economic and social categories, the number of papers increased by $48.6 \%$ and $73.7 \%$, respectively. However, the growth in the environmental category was only $16.3 \%$. This result shows that, although most studies focus on environmental studies, institutional aspects connect wider research topics when we look at the big picture. This finding may demonstrate that the SLCP's institutional and socioeconomic aspects have many direct and indirect links with its outcomes and that these relationships are not independent. In fact, many economists and ecologists have found that the socioeconomic and environmental effects may have certain links to implementation strategies. For example, Gauvin et al. [50] suggested that the dual goals of the program design are a barrier to improving cost-effectiveness. Moreover, the ecologist Cao [51] asserted that unsuitable afforestation design seems likely to worsen local water shortages.

\section{Results}

\subsection{What Criteria for the Program's Effectiveness are Described in the Literature?}

\subsubsection{Effective Implementation}

\subsubsection{Effectiveness of Targeting}

According to official document [52], the principle of targeting is that "sloping land suffering from serious soil erosion and that is low-yield should be afforested as much as possible under the plan approved by State Council; while government cannot force households to retire land with good production conditions and high yield that is causing no soil erosion". In other words, the targeting criteria are sloping and low-yield land. This official strategy is recognized by many researchers as a means through which the program achieves its goal of preventing soil erosion at the lowest possible cost $[25,50,53]$. For example, Uchida et al. [25] showed that targeting land on the basis of individual plot sizes, slopes and yield histories might maximize the environmental benefit and minimize payments. In the same vein, Gauvin et al. [50] further asserted that with the exception of land associated with high environmental benefits and lower opportunity costs, land managed by poorer households should have been considered. Additionally, Wang et al. [54] suggests that local heterogeneity must also be taken into account because local and regional biophysical and socioeconomic characteristics vary greatly based on the land's productivity and susceptibility to erosion.

\subsubsection{Stakeholder Engagement}

As an approach that is distinct from and innovative compared with conventional programs, the SLCP claims to be decentralized and voluntary [24]. It directly engages rural households with respect for local volunteerism and autonomy, abiding by the core principle of PES, which is defined by Wunder [8] as a 
voluntary transaction. As noted in The Economics of Ecosystems and Biodiversity report [55], "wide participation in decisions relating to PES design and implementation can help ensure transparency and acceptance and to avoid the covert privatization of common resources". Without adequate consultation and "bottom-up" initiatives, local people tend not to plant or properly maintain trees and grass [56], and as a result, survival and growth rates can be negatively affected $[34,56]$.

\subsubsection{Compliance}

The aspect of "conditionality" is considered critical for PES because it ensures that participants actually comply with their contracts [8]. Regarding SLCP, the term of conditionality was replaced by program compliance to define the trees/grasses planted on the enrolled land in terms of their quality, types and survival rates [24]. Compliance includes two essential parts: monitoring and sanctions. Effective and lasting monitoring, particularly internal monitoring and enforcement, should be a major component of implementing any PES program [32]. During the pilot phase, the most important compliance condition is the tree survival rate, which was $85 \%$ for the Yangtze River Basin regions and $70 \%$ for the Yellow River Basin regions [24]. Later, this standard was revised to a nationwide standard of $75 \%$ for full-scale implementation [24].

\subsubsection{Environmental Impact}

The main environmental impact of SLCP is found in forest ecosystems. Some environmental effects are immediately observable, such as the amount of land converted and afforested and the changes in vegetative cover [57]. By contrast, effects on flood control, carbon sequestration, and climate change, for example, are to a large extent inferred from changes in immediately observable factors [21], which makes it difficult to directly attribute program effects.

First, vegetation cover was accorded great significance in consolidating the reforestation achievements and effectively controlling soil erosion. Various studies, such as those by Zhou et al. [58], have used vegetation cover to evaluate the success of the SLCP. Indeed, Zhou et al. [59] found that the reduction of soil erosion in the Loess Plateau was partly attributable to the increase in forest coverage induced by the SLCP. Second, the program is considered to improve the physical properties of the soil structure and reduce nutrient loss to maintain soil fertility, in addition to decreasing river sediments [60]. The effects of the changes in surface runoff and sediment yields have been widely studied [61]. Third, the SLCP provides a good opportunity to restore biodiversity regions that have been destroyed or dramatically affected by human activity [62]. Fourth, large-scale afforestation under the SLCP will result in an extensive new forest and hence enhance the carbon sequestration capacity of China's terrestrial ecosystems [63].

\subsubsection{Socioeconomic Impact}

\subsubsection{Income Improvement}

A PES program can offer a means to increase the incomes of the rural poor and reduce risk by diversifying income sources, primarily through monetary payments [29]. Because most households in the target areas are poor and many are located on steeply sloped land, the program must be able to provide 
livelihoods to ensure the participation of households affected by the program [64]. Uchida et al. [25] assert that payments to households for entering their plots into the SLCP largely exceed the plots' opportunity costs; as a result, the average participating household should be better off by participating.

In addition to direct compensation, the new planting of commercial forests (such as fruit orchards) will continue to increase participants' income, and the government-invested newly built infrastructure will either provide income (e.g., fish ponds, livestock-raising facilities) or reduce households' costs (e.g., methane generators) even after government subsidies end [64].

\subsubsection{Labor Relocation}

The rapid loss of cropland has provided an abundance of labor for other businesses, and households can choose to allocate their labor off the farm market [59]. For example, the average cropland area of participating households in Wuqi in Shannxi Province dropped to approximately $30 \%$ of the original area during the 2004-2010 period [65]. These changes suggest a significant decline in on-farm labor use, and households might thus have much to gain from reallocating the surplus labor to off-farm employment. To solve liquidity constraints, it is easier for participating households to switch to non-farming activities than it is for non-participants [66]. Furthermore, this transition from on-farm to off-farm labor allocation and the diversification of revenue sources are keys to ensuring that the converted land is not returned to cropland [67].

\subsubsection{Poverty Alleviation}

The land owners who provide these environmental services are predominantly poor; consequently, a well-designed program can contribute to alleviating poverty [29]. The SFA explicitly states that poverty alleviation and restructuring agricultural production into a more environmentally and economically sustainable set of activities are goals of the SLCP [26]. Moreover, compensation under the SLCP is higher than opportunity costs, and one explanation for setting this compensation level is to benefit poor households [25]. However, the opportunity costs of retiring cropland and the operational costs of restoration vary with farming practices and natural conditions [35]. Therefore, it is worthwhile to have competitive participation selection based on the opportunity costs of local conditions [35].

\subsubsection{Sustainability of Forest}

Some studies $[25,51,68]$ suggest that the long-term effects and sustainability of the program are decided primarily by the households' behavior once payments cease. For example, Uchida [25] examined the issue of the sustainability of the SLCP through its potential to generate sufficient income that will continue after the formal program ends. In another example, Xu et al. [56] contended that the ultimate success of the SLCP depends on its ability to restructure the production practices of rural households so that they can increase the opportunity cost of their non-farm labor (e.g., livestock production and off-farm employment). To ensure the sustainability of forests, a sustainable livelihood should be guaranteed to the people losing their cropland. 


\subsection{Deviation between Effectiveness Criteria and Program Outcome}

The official evaluation report [43] of the SLCP presents the remarkable accomplishments of the program at the national level. Our analysis shows the differences between the national perspective and regional/local implementation.

\subsubsection{Effective Implementation}

One interesting finding is that the SLCP's spatial targeting has not always been achieved. Studies by Uchida et al. [25] and $\mathrm{Xu}$ et al. [46], for example, have found that in some cases, productive, low-sloped parcels have been included in the program, whereas in other cases, less productive high-sloped parcels have not. Uchida et al. [25] indicate that cost-effectiveness may have been compromised in practice due to overly rapid expansion and conflicts with local government priorities. Based on studies in northeast China, Wang and Maclaren [69] concluded that the targeting process was generally inefficient because productivity and environmental heterogeneity were ignored. There were many critics of the inefficient top-down implementation approach [24,35] associated with quota systems [46,70], and most blamed the local government, which preferred the easier-to-implement method of simplifying the plots-based selection [45,71].

Many studies [24,70] criticize the level of stakeholder engagement. For example, a survey conducted in Shaanxi, Gansu and Sichuan provinces in 2003 showed that approximately 53\% of households could choose whether to participate [24]. One survey in Hubei and Shanxi in 2011 showed that $86 \%$ of households participated in the program because they were required to do so by the government [72]. The most recent survey in 2014 in Yunnan found that only approximately 45\% of households were consulted about their willingness to participate in the program [30]. In practice, this consultation is commonly carried out at a village meeting that merely served to distribute required participation information instead of being an actual consultation [30]. Worse, due to the rushed initiation, even local planners do not have the knowledge to fully engage, resulting in even more confusion for participating households [32]. Many findings confirm that for some areas, implementation of the program proceeded in traditional top-down fashion $[24,32,45]$, without engaging households regarding their interest and willingness in participation [24,32], although the policy highlights the importance of local volunteerism [34,56]. Another critical point is that compliance has, to some extent, not been achieved. Compliance is monitored via a series of inspections conducted by various levels of government [24,71]. Because most enrolled land is in remote areas or in villages, village officials must check the land regularly. Furthermore, formal annual evaluations are conducted by township and county governments, and random but rare inspections are conducted by higher-level government entities or officials from the SFA [73]. According to the SFA, $97.4 \%$ of the enrolled land was monitored over the $1999-2005$ period, and $93 \%$ of it was deemed to pass the acceptance inspection [74]. However, many research results contradict these official reports; Bennett [24] found that the survival rate was 75\%, and Cao et al. [51] found that tree survival rates in the afforestation plots averaged only $55.7 \%$ in the first year after planting and $49 \%$ in the seventh year in northern Shaanxi Province. Similarly, the sanction mechanisms for non-compliance do not appear credible [24]. 


\subsubsection{Environmental Impact}

In addition to several studies $[75,76]$ that highlight the positive environmental effects of the SLCP, other studies, such as Cao et al. [77] and König et al. [78], also note some challenges with regarding to afforestation. First, a crucial aspect noted in this regard is that afforestation with unsuitable species may damage local water balances, even exhausting limited ground water, and may result in dead or dying trees. The potential regional effect of afforestation on watershed hydrology and water-resource management has not been thoroughly investigated [79]. On the one hand, forest areas in China are considered to play an important role in water cycling and water conservation, particularly with respect to flood reduction [80]. However, after crop land is converted to grassland, it is assumed that the water budget will be substantially disturbed because of the significant changes in vegetation components and in the vegetation cover period [81]. On the other hand, serious water shortages become progressively more limiting for further vegetation establishment, particularly in semi-arid steppes, which could ultimately lead to increasing desertification, as is the case in areas of Northern China [51,77], such as the Loess Plateau. Second, monoculture plantations and exotic species can also reduce biodiversity when they replace natural ecosystems [82]. In fact, during planting, there was widespread destruction of natural vegetation, such as the removal of natural herbaceous vegetation (i.e., grasses, forbs, herbs) to promote tree growth [51]. The monoculture plantations are also at high risk for insect and disease problems [83].

In this regard, Cao et al. [84] summarized the situation nicely, stating that the "huge investment to increase forest cover seems likely to exacerbate environmental degradation in environmentally fragile areas because it has ignored climate, pedological, hydrological, and landscape factors that would make a site unsuitable for afforestation".

However, forest cover change cannot always be credited to afforestation programs [85]; state forest policies may have been the main driver in the past, but private afforestation activities increasingly dominate the expansion of tree cover [85]. He et al. [36] provide further evidence that the contribution of the SLCP to forest cover is conditional on the institutional setting.

\subsubsection{Socioeconomic Impact}

The effects of the SLCP on participants' livelihoods are diverse, as reflected by key indicators such as income change and labor transfer. In different regions of China, the outcomes strongly depend on the local contexts and conditions. In most study cases $[65,86]$, the majority of households noted that the program actually increased their net incomes. Other studies, such as those by Song et al. [72] and Wang et al. [54], show that in some regions, households considered themselves to be worse off after participating in the SLCP. A longitudinal household study [23] doubted the efficiency of economic compensation because households received incomes that were either substantially higher or lower than their former crop incomes. In particular, it was noted that in the early implementation phase, compensation exceeds opportunity cost, and the program has received support from a large proportion of participants [25]. As time has passed, the prices of commodities have risen every year; however, the compensation standard is halved, making it a much smaller part of families' incomes. Consequently, it is reasonable for some households to have lost interest in the program and that some even want to return to farming. For example, in a survey conducted in 2005 in the Shaanxi Province, a large proportion 
(37.2\%) of participating households stated that they would return to cultivating forested areas and grassland once the project's subsidies end in 2018 [22]. In the province of Ningxia, only approximately $8 \%$ of households said that they would not re-convert their land to cropland following termination of the compensation [87].

In addition to compensation, income inequality [88] and the changes in income sources [47] induced by the SLCP have effects on income changes. By studying the Gini coefficient, Li et al. [88] found that income inequality is lower among participants than among non-participants. Xu et al. [89] also questioned the quality of development. Additionally, using the difference-in-differences model, Uchida et al. [25] found that the program has not induced significant changes in income sources except for the program payments. Using the same model, Yao et al. [90] showed that the income source does not significantly change apart from off-farm work, and the effect on crop production is not as negative as was once thought.

The argument of labor transfer has been studied intensively but remains unclear. Li et al. [88] found that the SLCP has not improved labor transfer to off-farm activities in the survey site because most participants still engage in traditional farming. By contrast, Yao et al. [90] showed that the program has accelerated the transfer of farming labor and has greatly stimulated income growth from off-farm opportunities. A 2003 study conducted by Uchida et al. [29] found no strong evidence that participants had changed their labor to off-farm work. Surprisingly, two years later, tracking the same group of households with the same method, researchers claimed that the program had significantly relaxed the liquidity constraints for participating households [66]. Other evidence also showed that participants began to shift the labor freed by the program to off-farm activities [67] and increasing numbers of households occupy with off-farm work in city areas because of higher income [23]. However, in the context of China's rapid expansion of urban employment, this labor transfer would doubtless occur even without the SLCP [91]. Another survey [91] is critical about explaining labor transfer by alleviating constraints but supports the idea that the transfer might involve a simple farm-to-nonfarm labor substitution. In summary, non-farm participation and labor supply may not be as sensitive to the program as the policy designers had thought, and the effects of labor transfer changed over the different study periods and differed from one site to another [92].

\subsection{What Types of Institutional Challenges are Described?}

With the program suffering from an imperfect institutional setting, some features are noted as challenges to its effectiveness in the literature. As the first article appearing in an international journal with regard to the institutional analysis of SLCP, Bennett et al. [24] examined the program design and implementation by assessing targeting, conditionality and participation autonomy. The top-down approach and budget distribution were frequently focused upon as problems [24,46]. In addition, Yin et al. [31] asked for more concerns on integrated program management, and He Jun [30] called for more attention to local dynamics in policy formulation. However, most of the literature has individually documented the effects of implementation and the institutional setting; much less of it has directly linked different institutional aspects to corresponding outcomes. Therefore, we summarize the following aspects of our literature sorting process under the umbrella of institutional challenges: (a) the quota system; (b) administrative budgeting; (c) a multi-goal approach; (d) a tree-planting strategy; (e) program adaptability; and (f) an institutional complementary policy. 


\subsubsection{The Quota System}

As noted by Bennett [24], the two main innovative elements of the SLCP are volunteerism and the direct engagement of participants. However, the de facto hierarchical (top-down) approach in the institutional setting destroyed the original design. According to the Regulations of the SLCP [41], the SLCP is implemented under a target responsibility system. The officials in the relevant departments of local governments at or above the county level will sign responsibility agreements with the higher levels of government that define the responsibilities. At the local level, the chief executives take responsibility for the outcomes, and forest bureaus take responsibility for actual implementation [41]. The performance of these tasks affects these officials' promotions, and there are even punishments for unsatisfactory performance or failures. Under this pressure to meet or exceed quotas, local government officials rushed households to retire much more land than was planned by the central government [31]. In principle, households should have been granted full autonomy in their choice of whether to participate. The government actually ignored the engagement of local people in implementing the program. A village leader survey [93] reported that in interviews with 40 village leaders, only three village leaders stated that participation in the SLCP was entirely voluntary. In most cases, participation was based on a combination of self-selection by households and final selection by the local government [93]. A 2014 study showed that farmers' participation in the SLCP was not voluntary [72].

To facilitate inspection and monitoring by higher-level government officials, some regions gave priority to sites near roads for conversion [24]. This practice resulted in a system that conspired not only to avoid targeting by the project but also to report its success [94]. As a result, some affected households were forced to subscribe to the scheme by village leaders to meet specific conversion targets [70]. Under the quota system, implementation originated from government agreements instead of being based on local conditions, land use practices, or household needs [70]. As result, some poor and environmentally critical areas received fewer quotas than they desired [71].

\subsubsection{Administrative Budgeting}

Some key administrative challenges of the SLCP include targeting, different agencies' coordination, compensation delivery, local proactive participation and after-program inspection [21,34,35,71]. However, these tasks are burdensome when local governments must pay the administrative costs from their own budgets $[24,46]$. Local governments have found other ways to benefit from the system by increasing land conversion quotas, exceeding quotas and bargaining for more subsidies [46]. Concurrently, they have sought to minimize administrative costs by including parcels that are contiguous regardless of steep slopes [95]. Consequently, a significant portion of non-sloping land was enrolled, whereas some steeply sloping land remained in cultivation [25].

Another crucial challenge is the program's poor monitoring [32,94]. For example, local budget crises have resulted in minimal monitoring and enforcement of the SLCP [70]. Additionally, given the remoteness of the forestation sites, which discourages monitoring and auditing, and the lack of funding and staffing for the projects, it makes sense for local officials simply to report successes and receive credit for them, particularly when they do not have the means to monitor the reforestation sites [94]. Shortfalls in delivered subsidies also occurred due to poor administrative budgeting [33]. Significant 
shortfalls in compensation received occurred in 2003, ranging from $24 \%-77 \%$ in a 2003 survey [24]. In a study by Xu et al. [96], approximately $50 \%$ of 1,026 households had received incomplete compensation.

\subsubsection{Compromise of a Multi-Goal Approach}

The dual goals of ecological conservation and alleviation of poverty place local government in a dilemma [24], weakening its ability to ensure program compliance. Withholding subsidies based on low survival rates can significantly dampen enthusiasm for the program and potentially harm households' welfare [24]. Additionally, the SLCP has acquired meaning that far exceeds the program itself. It was initially conceived as part of the "Open the West" campaign [49], which aimed to help China's western provinces catch up economically with the eastern provinces and transfer more rural labor to cities [21,97], which gave the SLCP a means for urbanization.

\subsubsection{Tree-Planting Strategy}

Opinions differ regarding the SLCP's afforestation strategy, which falls under the responsibility of the SFA [56]. For example, Cao [77] is critical of the SFA's over-enthusiasm for planting trees on sloping land, which has largely ignored local conditions. A study by Wang et al. [98] demonstrated that most of the dry land areas in the west have an annual rainfall of less than $400 \mathrm{~mm}$ and thus are suitable for growing only grass and drought-tolerant shrubs. Afforestation in vulnerable arid and semi-arid regions, such as those in northern Shaanxi Province, might increase the severity of water shortages, decrease vegetation cover in afforestation plots, and adversely affect biodiversity [51]. Different environments support different vegetation communities, and forests are not suitable for all areas [77]. Moreover, participating households advocate for the planting of trees over grass because of the longer compensation duration [23].

\subsubsection{Program Adaptability}

Studies [30,53] have indicated that flexible payments and a competitive selection process could be more efficient. Therefore, compensation should differ according to the benefits of certain plot types. The government offers two compensation schemes for the Yellow River Basin and the Yangtze River Basin. No formal pre-program analysis of participants' opportunity costs was conducted [24]. Instead, consideration of opportunity costs was based only on estimates of average regional yields. However, given the tremendous heterogeneity characterizing the two areas, it seems that both compensation schemes would fail to match either environmental benefits or income loss [25]. Regarding the SLCP, Wang et al. [54] concluded that the local and regional biophysical and socioeconomic characteristics do not appear to have been sufficiently considered in site selection.

Why does the socioeconomic effect of the program vary in different cases? One reasonable explanation is that the SLCP has different effects on different groups of people. Many researchers [24,25] criticize the program's adaptability because one single policy cannot fit all situations. There are many ways to classify people according to their different responses to the SLCP. Based on the resources they have for cropping, livestock husbandry or off-farm employment, Komarek et al. [99] classified different households into four categories. The study indicated that subsistence-oriented households were most 
likely to participate in the SLCP, whereas migration- and cropping-oriented households had less incentive to participate. Unlike the mainstream opinion of labor transfer [66], Cao et al. [22] found that many households prioritized agricultural development and that fewer wanted support in finding jobs in urban areas rather than assistance with tree and forage planting. These studies demonstrate that different people need different solutions and not a "one-size-fits-all" plan [22].

\subsubsection{Institutional Complementary Policy}

According to Yin et al. [31,40], the success of the SLCP program depends not only on its own stipulations but also on other related policies because the SLCP is devoted to fostering long-term sustainable rural livelihoods through measures such as tenure rights registration. However, the current land tenure system is characterized by insecure land rights due to the separation of land property rights and use rights [100]. Land property plays an important role when subsidies cease, and land rental rights can enhance the sustainability of the program by enabling households to pursue off-farm activities [31]. An analysis [101] also showed that households have a strong aversion for land redistribution and favor the development of more secure land rights (both property rights and rental rights).

Ideally, a market-based approach such as bidding and contracting can help to optimally match payer benefits with participation costs [102]. Programs such as the SLCP can adopt bidding processes to improve the effectiveness of targeting. Additionally, it enables the government to involve intermediaries [40] —including both for-profit and non-profit organizations - and these intermediaries might bridge the gap between the policy initiative at the top and local participants at the bottom [40]. However, it should be recognized that perfect targeting typically cannot be achieved in practice because of increasing transaction costs [31]. Therefore, although differentiated compensation cannot be based on the need of each local plot, it can be made according to plot types [31].

The implementation of the SLCP should be more closely integrated into a portfolio of policies addressing the rural economy. Access to rural credit [24], local livestock management [31], off-farm employment opportunities [66], and the removal of the legal barriers to rural-urban migration policy ("hukou" residency permit system) [100] might facilitate the effectiveness of the SLCP socioeconomically. Additionally, complementing the SLCP by other conservation programs would improve all the programs' effectiveness [21].

\section{Discussion}

To successfully reach its goals, the SLCP was claimed to be a decentralized and voluntary PES program; however, many institutional barriers have prevented it from being as innovative as it should be. Based on our analysis, we found the importance of institutional aspects, and how they affect the performance of the SLCP in this particular hybrid-governance type. There are multiple institutional driving forces that challenge the effectiveness of the SLCP: (1) the top-down governance regime with quota pressure has shaped the voluntary-based program into a campaign-style mobilization, and this regime has driven the program to quickly achieve tremendous land conversion, but at the cost of comprising local condition; (2) poor budgets have overburdened local governments, leading to poor targeting and loose monitoring, and the program can hardly succeed as its effectiveness wanes; (3) the trade-offs caused by conflicting goals - and particularly the dual goals of land conservation and poverty 
alleviation - have put local governments in a dilemma in which punishing poor performance tends to worsen the living conditions of poor households; (4) over-emphasized tree planting has increased the severity of water shortages, decreased vegetation cover, and adversely affected biodiversity; (5) lacking differentiation, the payment scheme did not take local heterogeneity and economic conditions into account in site selection; and (6) land tenure rights, technical support for tree planting and assistance in the labor market did not receive enough attention to ensure the SLCP's long-term impact. We outline the main relationships in Figure 5.

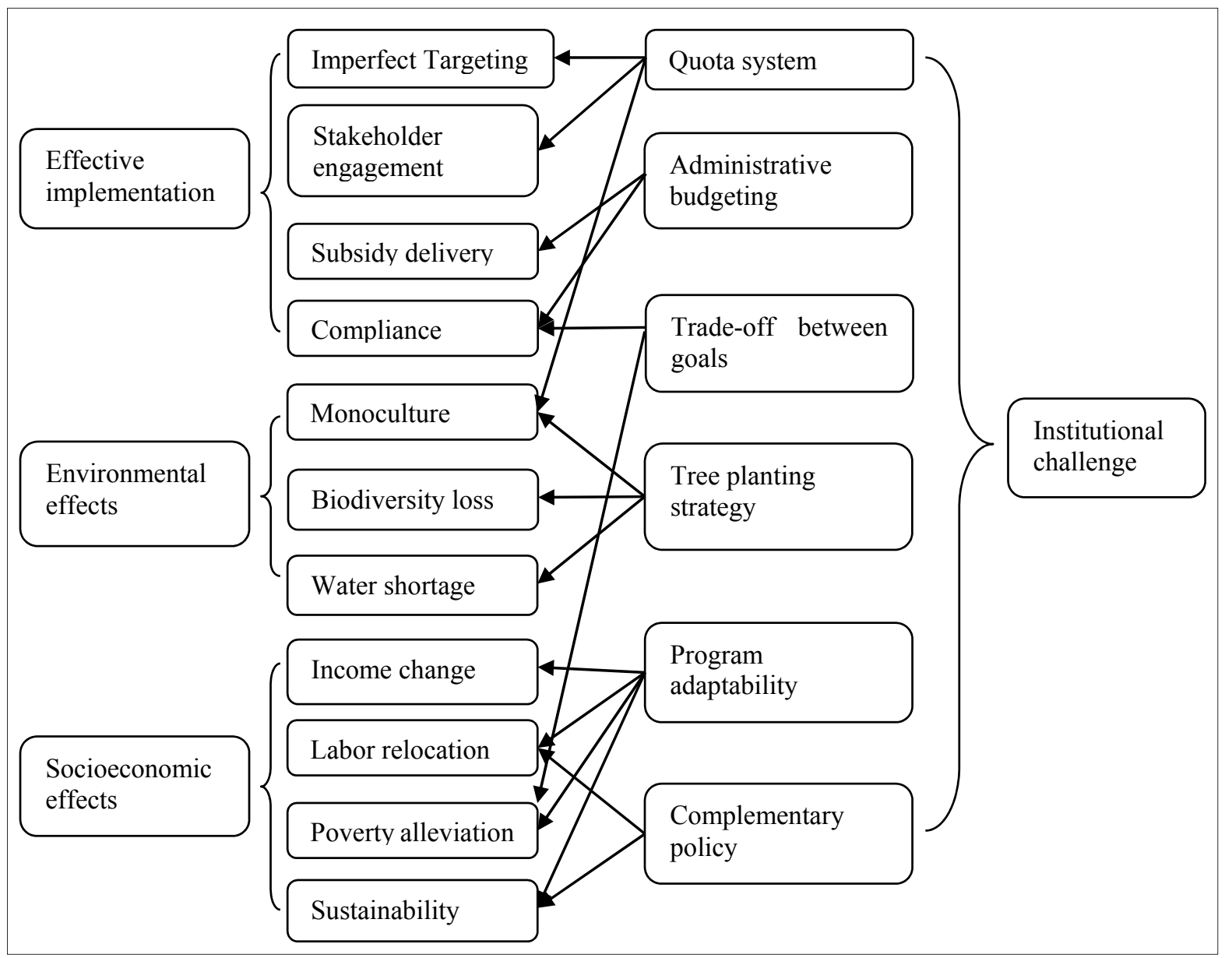

Figure 5. An illustration of the dependence of program effectiveness on implementation.

The arrows indicate the influence on, and the causality of, institutional challenges regarding the deviation between the criteria for program effectiveness and its outcomes. For example, the arrows of the quota system point to imperfect targeting, lack of voluntariness, and monoculture afforestation. Strong incentives to meet the quotas made local governments anxious to complete the task and in the end undermined the principle of voluntariness. There is substantial evidence in the literature that shows that the autonomy of the individual household has not been maintained and that participation is decided by the local government [24].

We acknowledge that the criteria for effectiveness in this figure are not independent of one another. For example, targeting is an element of effective implementation; however, it also causes vegetation cover and livelihood changes. Because we only discuss the deviation between institutional settings and the effectiveness criteria in this paper, we simply place them in different dimensions. Additionally, we 
admit the relationships discussed above are by no means an exhaustive description of the complex set of interrelationships between the effectiveness of implementation, environmental effects, socioeconomic effects and institutional challenges. In this figure, we do not intend to precisely reflect these dependencies, but we instead visually summarize the challenges and how they influence the program's implementation and its effects. Further empirical analysis is needed to testify and support the remarks of this review.

\section{Conclusions}

In this study, we analyzed the key institutional challenges faced by the Chinese PES, the SLCP. Based on a broad literature survey $(n=164)$, we identified the following four institutional aspects in our analysis: (1) program effectiveness (implementation and effects); (2) the difference between program objectives and achievements; (3) institutional challenges; and (4) the dependence of the identified lack of effectiveness on these challenges.

The targeting of the SLCP introduced challenges regarding household participation. In some cases, stakeholder participation appeared less vulnerable, partly as a result of administrative (and pragmatic) implementation issues, the large size of the program and the (relatively short) implementation time allotted. For many households, the program offered new income sources. On the one hand, it was noted that participating households could benefit from the shifting from on-farm to off-farm activities for better economic opportunities. On the other hand, with growing economic development, compensatory payments appeared to be less attractive, and some participating households actually expressed their intention to reconvert their land after the program ends; although evidence showed more and more farmers have off-farm jobs, indicating less need for arable land [23]. The key environmental challenges identified included the selection of appropriate tree species and locations (e.g., tree mortality/survival, water problems, and household issues with maintenance). Nevertheless, these consequences might be linked to certain institutional challenges that made the implementation deviate from the criteria for effectiveness. Studies have shown a large PES program such as the SLCP is a complex and dynamic process in which many relevant actors interact and evolve [32]. From our study, we argue that the program's effectiveness is a result of interacting driving forces, whereas institutional factors such as quota system, program management and relating policies play a key role in shaping the outcome.

This study shows that the concept of PES might be successfully employed in China. In this case, the PES concept provides the basis for considering imperfect institutional settings featuring different environmental and socioeconomic conditions simultaneously. If key relationships are well understood and addressed, the effectiveness of the SLCP can thus be improved. A key finding of this study highlights the dependence of program effectiveness criteria on institutional settings under a hybrid governance regime (a mixture of top-down and voluntary approaches). Using a systematic approach, we conclude that large-scale government-driven PES programs could benefit from adopting the widely accepted principles underlying a typical PES as reflected in policy design, implementation, monitoring and adjustment.

\section{Supplementary Materials}

Supplementary materials can be accessed at: http://www.mdpi.com/2071-1050/7/5/5564/s1. 


\section{Acknowledgments}

We would like to express our sincere thanks to our colleagues, Barbara Schröter, Claudia Sattler, Claas Meyer and Sarah Schomers at ZALF and to Chao Wang at IGSRNN for their valuable comments on this paper. Support from the Technical Support Program (No. 2013BAC03B04) and National Key Project for Basic Research (973) (No. 2014CB954302) of the Ministry of Science and Technology of China is appreciated. The authors would also like to gratefully acknowledge the efforts of the anonymous reviewers and editors of the special issue.

\section{Author Contributions}

All of the authors jointly designed and wrote the manuscript. It is part of Cheng Chen's PhD study and he wrote the main part. Bettina Matzdorf wrote the introduction part, Hannes J. König wrote the conclusion part and Lin Zhen contributed to form the structure. All of the authors participated in the revision process and the final manuscript has been approved by all authors.

\section{Conflicts of Interest}

The authors declare no conflicts of interest.

\section{References}

1. Kinzig, A.; Perrings, C.; Chapin, F.; Polasky, S.; Smith, V.; Tilman, D.; Turner, B. Paying for Ecosystem Services-Promise and Peril. Science 2011, 334, 603-604.

2. Van Hecken, G.; Bastiaensen, J. Payments for ecosystem services: Justified or not? A political view. Environ. Sci. Policy 2010, 13, 785-792.

3. Coase, R.H. The problem of social cost. J. Law Econ. 1960, 3, 1-44.

4. Hahnel, R.; Sheeran, K. Misinterpreting the Coase theorem. J. Econ. Issues 2009, 43, 215-238.

5. Gómez-Baggethun, E.; de Groot, R.; Lomas, P.L.; Montes, C. The history of ecosystem services in economic theory and practice: From early notions to markets and payment schemes. Ecol. Econ. 2010, 69, 1209-1218.

6. Matzdorf, B.; Sattler, C.; Engel, S. Institutional frameworks and governance structures of PES schemes. For. Policy Econ. 2013, 37, 57-64.

7. Schomers, S.; Matzdorf, B. Payments for ecosystem services: A review and comparison of developing and industrialized countries. Ecosyst. Serv. 2013, 6, 16-30.

8. Wunder, S. Payments for Environmental Services: Some Nuts and Bolts; CIFOR: Jakarta, Indonesia, 2005; Volume 42.

9. Matzdorf, B.; Biedermann, C.; Meyer, C.; Nicolaus, K.; Sattler, C.; Schomers, S. Was Kostet Die Welt? Payments for Ecosystem Services in der Praxis; Oekom: Munich, Germany, 2014.

10. Engel, S.; Pagiola, S.; Wunder, S. Designing payments for environmental services in theory and practice: An overview of the issues. Ecol. Econ. 2008, 65, 663-674.

11. Vatn, A. An institutional analysis of payments for environmental services. Ecol. Econ. 2010, 69, $1245-1252$. 
12. Sattler, C.; Matzdorf, B. PES in a nutshell: From definitions and origins to PES in practice-Approaches, design process and innovative aspects. Ecosyst. Serv. 2013, 6, 2-11.

13. Muradian, R.; Rival, L. Between markets and hierarchies: The challenge of governing ecosystem services. Ecosyst. Serv. 2012, 1, 93-100.

14. Liu, J.; Diamond, J. Revolutionizing China's environmental protection. Science 2008, 319, 37-38.

15. Liu, J.; Diamond, J. China's environment in a globalizing world. Nature 2005, 435, 1179-1186.

16. Zhang, Q.; Bennett, M.T.; Kannan, K.; Jin, L. Payments for Ecological Services and Eco-Compensation: Practices and innovations in the People's Republic of China; Asian Development Bank: Mandaluyong City, Philippines, 2010.

17. The China Council for International Cooperation on Environment and Development (CCICED). Eco-Compensation Mechanisms and Policies in China; The China Council for International Cooperation on Environment and Development: Beijing, China, 2006.

18. Bennett, M.T. Markets for Ecosystem Services in China: An Exploration of China' $s$ "Eco-Compensation" and Other Market Based Environmental Policies, Forest Trends: Washington, DC, USA, 2009.

19. Zhen, L.; Zhang, H. Payment for ecosystem services in China: An overview. Living Rev. Landsc. Res. 2011, 5, 1-24.

20. Liu, J.; Yang, W. Integrated assessments of payments for ecosystem services programs. Proc. Natl. Acad. Sci. USA 2013, 110, 16297-16298.

21. Liu, J.; Li, S.; Ouyang, Z.; Tam, C.; Chen, X. Ecological and socioeconomic effects of China's policies for ecosystem services. Proc. Natl. Acad. Sci. USA 2008, 105, 9477-9482.

22. Cao, S.; Xu, C.; Chen, L.; Wang, X. Attitudes of farmers in China's northern Shaanxi Province towards the land-use changes required under the Grain for Green project, and implications for the project's success. Land Use Policy 2009, 26, 1182-1194.

23. Yin, R.; Liu, C.; Zhao, M.; Yao, S.; Liu, H. The implementation and impacts of China's largest payment for ecosystem services program as revealed by longitudinal household data. Land Use Policy 2014, 40, 45-55.

24. Bennett, M.T. China's Sloping Land Conversion Program: Institutional innovation or business as usual? Ecol. Econ. 2008, 65, 699-711.

25. Uchida, E.; Xu, J.; Rozelle, S. Grain for green: Cost-effectiveness and sustainability of China's conservation set-aside program. Land Econ. 2005, 81, 247-264.

26. State Forest Administration. Sloping Land Conversion Program Plan (2001-2010); State Forest Administration: Beijing, China, 2003.

27. Wunder, S.; Engel, S.; Pagiola, S. Taking stock: A comparative analysis of payments for environmental services programs in developed and developing countries. Ecol. Econ. 2008, 65, 834-852.

28. Zhang, K.; Dang, H.; Tan, S.; Cheng, X.; Zhang, Q. Change in soil organic carbon following the 'Grain-for-Green' programme in China. Land Degrad. Dev. 2010, 21, 13-23.

29. Uchida, E.; Xu, J.; Xu, Z.; Rozelle, S. Are the poor benefiting from China's land conservation program? Environ. Dev. Econ. 2007, 12, 593-620.

30. He, J. Governing forest restoration: Local case studies of Sloping Land Conversion Program in southwest China. For. Policy Econ. 2014, 46, 30-38. 
31. Yin, R.; Yin, G.; Li, L. Assessing China's ecological restoration programs: What's been done and what remains to be done? Environ. Manag. 2010, 45, 442-453.

32. Yin, R.; Liu, T.; Yao, S.; Zhao, M. Designing and implementing payments for ecosystem services programs: Lessons learned from China's cropland restoration experience. For. Policy Econ. 2013, $35,66-72$.

33. Yin, R.; Zhao, M. Ecological restoration programs and payments for ecosystem services as integrated biophysical and socioeconomic processes-China's experience as an example. Ecol. Econ. 2012, 73, 56-65.

34. Yin, R.; Yin, G. China's primary programs of terrestrial ecosystem restoration: Initiation, implementation, and challenges. Environ. Manag. 2010, 45, 429-441.

35. Yin, R.; Zhao, M.; Yao, S. Designing and implementing payments for ecosystem services programs: What lessons can be learned from China's experience of restoring degraded cropland? Environ. Sci. Technol. 2014, 48, 19-20.

36. He, J.; Lang, R.; Xu, J. Local dynamics driving forest transition: Insights from upland villages in southwest China. Forests 2014, 5, 214-233.

37. Hejnowicz, A.P.; Raffaelli, D.G.; Rudd, M.A.; White, P.C.L. Evaluating the outcomes of payments for ecosystem services programmes using a capital asset framework. Ecosyst. Serv. 2014, 9, 83-97.

38. Ostrom, E. A general framework for analyzing sustainability of social-ecological systems. Science 2009, 325, 419-422.

39. Yin, R. Assessing China's ecological restoration programs. Environ. Manag. 2010, 45, 425-428.

40. Yin, R.; Xu, J.; Li, Z.; Liu, C. China's ecological rehabilitation: The unprecedented efforts and dramatic impacts of reforestation and SLCP protection in western China. China Environ. Ser. 2005, 6, 17-32.

41. State Council. The Regulation of SLCP; State Council: Beijing, China, 2002.

42. State Forest Administration. China Forestry Statistic Yearbook 2012; China Forestry Publishing House: Beijing, China, 2013.

43. State Forest Administration. National Report of Ecological Assessment of SLCP; China Forestry Publishing House: Beijing, China, 2013.

44. State Council. The Notification of Improving the Policy of SLCP; State Council: Beijing, China, 2007.

45. Zuo, T. Part II. The Sloping Land Conversion Program (SLCP). Chapter 3. Implementation of the SLCP. In Implementing the Natural Forest Protection Program and the Sloping Land Conversion Program: Lessons and Policy Implications; Xu, J., Katsigris, E., White, T.A., Eds.; China Forestry Publishing House: Beijing,China, 2001.

46. Xu, Z.G.; Bennett, M.T.; Tao, R.; Xu, J.T. China's Sloping Land Conversion Programme four years on: Current situation and pending issues. Int. For. Rev. 2004, 6, 317-326.

47. He, J.; Sikor, T. Notions of justice in payments for ecosystem services: Insights from China's Sloping Land Conversion Program in Yunnan Province. Land Use Policy 2015, 43, 207-216.

48. Tu, Q.; Mol, A.P.; Zhang, L.; Ruben, R. How do trust and property security influence household contributions to public goods?: The case of the Sloping Land Conversion Program in China. China Econ. Rev. 2011, 22, 499-511. 
49. Trac, C.J.; Schmidt, A.H.; Harrell, S.; Hinckley, T.M. Environmental reviews and case studies: Is the returning farmland to forest program a success? Three case studies from Sichuan. Environ. Pract. 2013, 15, 350-366.

50. Gauvin, C.; Uchida, E.; Rozelle, S.; Xu, J.; Zhan, J. Cost-effectiveness of payments for ecosystem services with dual goals of environment and poverty alleviation. Environ. Manag. 2010, $45,488-501$.

51. Cao, S.; Chen, L.; Yu, X. Impact of China's Grain for Green project on the landscape of vulnerable arid and semi-arid agricultural regions: A case study in northern Shaanxi Province. J. Appl. Ecol. 2009, 46, 536-543.

52. State Council. Several Opinions Regarding Further Improving the Policy Measures of SLCP; State Council: Beijing, China, 2002.

53. Chen, X.; Lupi, F.; Vina, A.; He, G.; Liu, J. Using cost-effective targeting to enhance the efficiency of conservation investments in payments for ecosystem services. Conserv. Biol. 2010, 24, 1469-1478.

54. Wang, C.; Ouyang, H.; Maclaren, V.; Yin, Y.; Shao, B.; Boland, A.; Tian, Y. Evaluation of the economic and environmental impact of converting cropland to forest: A case study in Dunhua County, China. J. Environ. Manag. 2007, 85, 746-756.

55. The Economics of Ecosystems and Biodiversity. The Economics of Ecosystems and Biodiversity: Ecological and Economic Foundations; Earthscan: London, UK, 2010.

56. Xu, J.; Yin, R.; Li, Z.; Liu, C. China's ecological rehabilitation: Unprecedented efforts, dramatic impacts, and requisite policies. Ecol. Econ. 2006, 57, 595-607.

57. Long, H.L.; Heilig, G.K.; Wang, J.; Li, X.B.; Luo, M.; Wu, X.Q.; Zhang, M. Land use and soil erosion in the upper reaches of the Yangtze River: Some socio-economic considerations on China's Grain-for-Green programme. Land Degrad. Dev. 2006, 17, 589-603.

58. Zhou, H.; van Rompaey, A.; Wang, J. Detecting the impact of the "Grain for Green" program on the mean annual vegetation cover in the Shaanxi Province, China using spot-VGT NDVI data. Land Use Policy 2009, 26, 954-960.

59. Zhou, D.; Zhao, S.; Zhu, C. The Grain for Green project induced land cover change in the Loess Plateau: A case study with Ansai County, Shanxi Province, China. Ecol. Indic. 2012, 23, 88-94.

60. Liu, X.; Zhang, W.; Liu, Z.; Qu, F.; Tang, X. Changes in species diversity and above-ground biomass of shrubland over long-term natural restoration process in the Taihang mountain in north China. Plant Soil Environ. 2011, 57, 505-512.

61. Zhou, Z.; Gan, Z.; Shangguan, Z.P.; Dong, Z. China's Grain for Green program has reduced soil erosion in the upper reaches of the Yangtze River and the middle reaches of the Yellow River. Int. J. Sustain. Dev. World Ecol. 2009, 16, 234-239.

62. Xu, J.-Y.; Chen, L.-D.; Lu, Y.-H.; Fu, B.-J. Sustainability evaluation of the Grain for Green project: From local people's responses to ecological effectiveness in Wolong nature reserve. Environ. Manag. 2007, 40, 113-122.

63. Persson, M.; Moberg, J.; Ostwald, M.; Xu, J. The Chinese Grain for Green programme: Assessing the carbon sequestered vialand reform. J. Environ. Manag. 2013, 126, 142-146.

64. Cao, S.; Zhong, B.; Yue, H.; Zeng, H.; Zeng, J. Development and testing of a sustainable environmental restoration policy on eradicating the poverty trap in China's Changting County. Proc. Natl. Acad. Sci. USA 2009, 106, 10712-10716. 
65. Lin, Y.; Yao, S. Impact of the Sloping Land Conversion Program on rural household income: An integrated estimation. Land Use Policy 2014, 40, 56-63.

66. Uchida, E.; Rozelle, S.; Xu, J. Conservation payments, liquidity constraints, and off-farm labor: Impact of the Grain-for-Green program on rural households in China. Am. J. Agric. Econ. 2009, 91, 70-86.

67. Groom, B.; Grosjean, P.; Kontoleon, A.; Swanson, T.; Zhang, S. Relaxing rural constraints: A 'win-win' policy for poverty and environment in China? Oxford Econ. Pap. 2010, 62, 132-156.

68. Chen, X.; Lupi, F.; He, G.; Ouyang, Z.; Liu, J. Factors affecting land reconversion plans following a payment for ecosystem service program. Biol. Conserv. 2009, 142, 1740-1747.

69. Wang, C.; Maclaren, V. Evaluation of economic and social impacts of the Sloping Land Conversion Program: A case study in Dunhua county, China. For. Policy Econ. 2012, 14, 50-57.

70. Kolinjivadi, V.K.; Sunderland, T. A review of two payment schemes for watershed services from China and Vietnam: The interface of government control and PES theory. Ecol. Soc. 2012, 17, 10.

71. Weyerhaeuser, H.; Wilkes, A.; Kahrl, F. Local impacts and responses to regional forest conservation and rehabilitation programs in China's northwest Yunnan Province. Agric. Syst. 2005, $85,234-253$.

72. Song, C.; Zhang, Y.; Mei, Y.; Liu, H.; Zhang, Z.; Zhang, Q.; Zha, T.; Zhang, K.; Huang, C.; $\mathrm{Xu}, \mathrm{X}$; et al. Sustainability of forests created by China's Sloping Land Conversion Program: A comparison among three sites in Anhui, Hubei and Shanxi. For. Policy Econ. 2014, 38, 161-167.

73. Liao, X.; Zhang, Y. Economic impacts of shifting sloping farm lands to alternative uses. Agric. Syst. 2008, 97, 48-55.

74. State Forest Administration. The Overall Report about Outcome of SLCP; State Forest Administration: Beijing, China, 2007.

75. Deng, L.; Shangguan, Z.-P.; Li, R. Effects of the Grain-for-Green program on soil erosion in China. Int. J. Sediment Res. 2012, 27, 120-127.

76. Zhao, F.Z.; Han, X.H.; Yang, G.H.; Feng, Y.Z.; Ren, G.X. Soil structure and carbon distribution in subsoil affected by vegetation restoration. Plant Soil Environ. 2014, 60, 21-26.

77. Cao, S. Why large-scale afforestation efforts in China have failed to solve the desertification problem. Environ. Sci. Technol. 2008, 42, 1826-1831.

78. König, H.J.; Zhen, L.; Helming, K.; Uthes, S.; Yang, L.; Cao, X.; Wiggering, H. Assessing the impact of the Sloping Land Conversion Programme on rural sustainability in Guyuan, western China. Land Degrad. Dev. 2012, 25, 385-396

79. Zhang, Y.; Liu, S.; Wei, X.; Liu, J.; Zhang, G. Potential impact of afforestation on water yield in the Subalpine region of southwestern China. J. Am. Water Resour. Assoc. 2008, 44, 1144-1153.

80. Sun, G.; Zhou, G.; Zhang, Z.; Wei, X.; McNulty, S.G.; Vose, J.M. Potential water yield reduction due to forestation across China. J. Hydrol. 2006, 328, 548-558.

81. Qiu, G.Y.; Xie, F.; Feng, Y.C.; Tian, F. Experimental studies on the effects of the "Conversion of Cropland to Grassland Program" on the water budget and evapotranspiration in a semi-arid steppe in Inner Mongolia, China. J. Hydrol. 2011, 411, 120-129.

82. Zhai, D.-L.; Xu, J.-C.; Dai, Z.-C.; Cannon, C.H.; Grumbine, R.E. Increasing tree cover while losing diverse natural forests in tropical Hainan, China. Reg. Environ. Chang. 2014, 14, 611-621. 
83. Liu, J.; Ouyang, Z.; Pimm, S.L.; Raven, P.H.; Wang, X.; Miao, H.; Han, N. Protecting China's biodiversity. Science 2003, 300, 1240-1241.

84. Cao, S.; Chen, L.; Shankman, D.; Wang, C.; Wang, X.; Zhang, H. Excessive reliance on afforestation in China's arid and semi-arid regions: Lessons in ecological restoration. Earth Sci. Rev. 2011, 104, 240-245.

85. Frayer, J.; Sun, Z.; Mueller, D.; Munroe, D.K.; Xu, J. Analyzing the drivers of tree planting in Yunnan, China, with Bayesian networks. Land Use Policy 2014, 36, 248-258.

86. Peng, H.; Cheng, G.; Xu, Z.; Yin, Y.; Xu, W. Social, economic, and ecological impacts of the "Grain for Green" project in China: A preliminary case in Zhangye, northwest China. J. Environ. Manag. 2007, 85, 774-784.

87. Zhang, L.; Tu, Q.; Mol, A.P.J. Payment for environmental services: The Sloping Land Conversion Program in Ningxia Autonomous Region of China. China World Econ. 2008, 16, 66-81.

88. Li, J.; Feldman, M.W.; Li, S.; Daily, G.C. Rural household income and inequality under the Sloping Land Conversion Program in western China. Proc. Natl. Acad. Sci. USA 2011, 108, 7721-7726.

89. Xu, J.; Tao, R.; Xu, Z.; Bennett, M.T. China's Sloping Land Conversion Program: Does expansion equal success? Land Econ. 2010, 86, 219-244.

90. Yao, S.; Guo, Y.; Huo, X. An empirical analysis of the effects of China's land conversion program on farmers' income growth and labor transfer. Environ. Manag. 2010, 45, 502-512.

91. Kelly, P.; Huo, X. Land retirement and nonfarm labor market participation: An analysis of China's Sloping Land Conversion Program. World Dev. 2013, 48, 156-169.

92. Liu, T.; Liu, C.; Liu, H.; Wang, S.; Rong, Q.; Zhu, W. Did the key priority forestry programs affect income inequality in rural China? Land Use Policy 2014, 38, 264-275.

93. Zhang, S.; Swanson, T.; Kontoleon, A. Impacts of Compensation Policies in Reforestation Programs, Report of the Environment and Poverty Programme to China Council for International Cooperation in Environment and Development (CCICED); CCICED: Beijing, China, 2005.

94. Trac, C.J.; Harrell, S.; Hinckley, T.M.; Henck, A.C. Reforestation programs in southwest China: Reported success, observed failure, and the reasons why. J. Mt. Sci. 2007, 4, 275-292.

95. Kelly, P.; Huo, X. Do farmers or governments make better land conservation choices? Evidence from China's Sloping Land Conversion Program. J. For. Econ. 2013, 19, 32-60.

96. Jintao $\mathrm{Xu}, \mathrm{Y} . \mathrm{C}$. The socioeconomic impacts and sustainability of the SLCP. In Implementing the Natural Forest Protection Program and the Sloping Land Conversion Program: Lessons and Policy Recommendations; Xu, J., Katsigris, E., White, T.A., Eds.; CCICED-Task Force on Forests and Grasslands, China Forestry Publishing House: Beijing, China, 2001.

97. Zhen, N.; Fu, B.; Lü, Y.; Zheng, Z. Changes of livelihood due to land use shifts: A case study of Yanchang County in the Loess Plateau of China. Land Use Policy 2014, 40, 28-35.

98. Wang, X.; Lu, C.; Fang, J.; Shen, Y. Implications for development of Grain-for-Green policy based on cropland suitability evaluation in desertification-affected north China. Land Use Policy 2007, 24, 417-424.

99. Komarek, A.M.; Shi, X.; Heerink, N. Household-level effects of China's Sloping Land Conversion Program under price and policy shifts. Land Use Policy 2014, 40, 36-44. 
100. Li, L.; Tsunekawa, A.; Tsubo, M.; Koike, A.; Wang, J. Efficiency and its determinant factors for smallholder farms in the Grain for Green program on the Loess Plateau, China. J. Food Agric. Environ. 2010, 8, 772-778.

101. Grosjean, P.; Kontoleon, A. How sustainable are sustainable development programs? The case of the Sloping Land Conversion Program in China. World Dev. 2009, 37, 268-285.

102. Ferraro, P.J. Asymmetric information and contract design for payments for environmental services. Ecol. Econ. 2008, 65, 810-821.

(C) 2015 by the authors; licensee MDPI, Basel, Switzerland. This article is an open access article distributed under the terms and conditions of the Creative Commons Attribution license (http://creativecommons.org/licenses/by/4.0/). 